\title{
CD147 silencing via RNA interference reduces tumor cell invasion, metastasis and increases chemosensitivity in pancreatic cancer cells
}

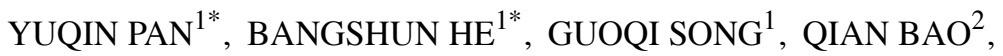 \\ ZHIPENG TANG ${ }^{1}$, FULIANG TIAN ${ }^{2}$ and SHUKUI WANG ${ }^{1}$ \\ ${ }^{1}$ Central Laboratory, Nanjing First Hospital, Nanjing Medical University, Nanjing, Jiangsu 210006; \\ ${ }^{2}$ Department of Life Sciences, Nanjing Normal University, Nanjing, Jiangsu 210046, P.R. China
}

Received February 1, 2012; Accepted March 5, 2012

DOI: 10.3892/or.2012.1729

\begin{abstract}
CD147, which belongs to the immunoglobulin superfamily, is a multifunctional glycoprotein that has been shown to increase tumor invasion, metastasis and multidrug resistance. To define the role of CD147 in invasion and metastasis more precisely, we utilized gene silencing to inhibit the expression of CD147 in pancreatic cancer cells. We observed that CD147 expression was significantly impeded at both the mRNA and protein levels and resulted in a decrease of MMP-2 and MMP-9 activities. There was also a decrease of MCT1 expression in the invasion and metastasis potential of pancreatic cancer cells, as well as increased chemosensitivity to gemcitabine in Panc-1 cells. Overall, these results suggest that CD147 plays an important role in the invasion, metastasis and chemosensitivity of the human pancreatic cancer cell line Panc-1, indicating that CD147 may be a promising therapeutic target for pancreatic cancer.
\end{abstract}

\section{Introduction}

Pancreatic cancer is a malignancy with an extremely poor prognosis and is refractory to conventional chemotherapy and radiotherapy. Despite efforts in the past years, conventional treatment approaches, such as surgery, radiation,

Correspondence to: Dr Shukui Wang, Nanjing First Hospital, Nanjing Medical University, Nanjing, Jiangsu 210006, P.R. China

E-mail: shukwang@163.com

*Contributed equally

Abbreviations: MMP, matrix metalloproteinase; MCT, monocarboxylate transporter; LDH, lactate dehydrogenase; shRNA, short hairpin RNA; PPC, plasma peak concentrations

Key words: CD147, invasion, metastasis, multidrug resistance, pancreatic cancer, gemcitabine chemotherapy, or combinations of these, the mortality rate of pancreatic cancer still remains high (1-4). Therefore, it can be effectively diagnosed, prevented, and treated only by developing a detailed understanding of the molecular biology of underlying pancreatic cancer formation and progression.

CD147 (EMMPRIN) is a highly glycosylated cell surface transmembrane protein that belongs to the immunoglobulin superfamily (5), and it is thought to be involved in inflammation, neural-glial interaction, and virus infection (6-9). CD147 is found to be highly expressed in a variety of malignant human cancers, including malignancies of the pancreas $(6,10,11)$, and it induces tumor cell invasion by stimulating the production of matrix metalloproteinases (MMPs), resulting in tumor invasion and metastasis (12). In addition, CD147 plays a pivotal role as a chaperone for the proper plasma membrane expression and the activity of monocarboxylate transporters (MCTs), particularly MCT1 and MCT4 (13-15). MCTs are among the most important cellular $\mathrm{pH}$ regulators likely involved in cancer $\mathrm{pH}$ homeostasis (16-18). The MCT family has fourteen members (19), six of which have been functionally characterized, but only MCT1-MCT4 have been shown to catalyze the proton-coupled transport of lactate (20-24). Many studies have demonstrated that $\mathrm{CD} 147$ acts as an essential chaperone to take MCT1 and MCT4 to the plasma membrane where the MCTs and CD147 are tightly associated $(13,25)$.

CD147 is also involved in multidrug resistance of cancer cells via hyaluronan-mediated activation of ErbB2 signaling and cell survival pathway activities, but the mechanism of CD147 in multidrug resistance of pancreatic cancer remains elusive (26-28). We demonstrate here that CD147 silencing inhibits pancreatic cancer cell invasion and metastasis and increases chemosensitivity to gemcitabine. Our results support the concept that CD147 expression is associated with the malignant potential of cancer cells, since it sustains the expression and function of MMPs and MCTs.

\section{Materials and methods}

Plasmid constructs and generation of stable cell clones. The vector pSilencer 3.1-H1 neo (Ambion) was used to generate short hairpin RNA (shRNA) specifically for CD147. Two pairs 
Table I. Sequences of the designed CD147 specific shRNAs.

\begin{tabular}{ll}
\hline shRNA & \multicolumn{1}{c}{ Sequence } \\
\hline shRNA1 & 5'-ATCCGTCGTCAGAACACATCAACTTCAAGAGAGTTGATGTGTTCTGACGACTTTTTTGGAAA-3' \\
& 5'-AGCTTTTCAAAAAAGTCGTCAGAACACATCAACTCTCTTGAAGTTGATGTGTTCTGACGACG-3' \\
shRNA2 & 5'-GATCCGTGACAAAGGCAAGAACGTCTTCAAGAGAGACGTTCTTGCCTTTGTCATTTTTTGGAAA-3' \\
& 5'-AGCTTTCCAAAAAATGACAAAGGCAAGAACGTCTCTCTTGAAGACGTTCTTGCCTTTGTCACG-3' \\
shRNA-control & 5'-GATCCACTACCGTTGTTATAGGTGTTCAAGAGACACCTATAACAACGGTAGTTTTTTGGAAA-3' \\
& 5'-AGCTTTTCCAAAAAAACTACCGTTGTTATAGGTGTCTCTTGAACACCTATAACAACGGTAGTG-3' \\
\hline
\end{tabular}

Table II. Primers of CD147, MCT1, MCT4 and $\beta$-actin for real-time PCR.

\begin{tabular}{ll}
\hline Target & \multicolumn{1}{c}{ Primers } \\
\hline CD147 & $\begin{array}{l}\text { Sense: 5'-CCATGCTGGTCTGCAAGTCAG-3' } \\
\text { Antisense: 5'-CCGTTCATGAGGGCCTTGTC-3' }\end{array}$ \\
MCT1 & $\begin{array}{l}\text { Sense: 5'-CACTTAAAATGCCACCAGCA-3' } \\
\text { Antisense: 5'-AGAGAAGCCGATGGAAATGA-3' }\end{array}$ \\
MCT4 & $\begin{array}{l}\text { Sense: 5'-GTTGGGTTTGGCACTCAACT-3' } \\
\text { Antisense: 5'-GAAGACAGGGCTACCTGCTG-3' }\end{array}$ \\
$\beta$-actin & $\begin{array}{l}\text { Sense: 5'-CTGGAACGGTGAAGGTGACA-3' } \\
\text { Antisense: 5'-AAGGGACTTCCTGTAACAACGCA-3' }\end{array}$ \\
&
\end{tabular}

of template oligonucleotides, each encoding one of the target sequences, were designed and synthesized (designated as shRNA1 and shRNA2, respectively), and the scrambled control sequence (designated as shRNA-control) was also synthesized (Table I). Subsequently, these oligonucleotides were cloned into the plasmid pSilencer 3.1-H1 neo, using restriction endonuclease BamHI and HindIII. These recombinant vectors were designated as pH1-shRNA-control, pH1-shRNA1 and pH1-shRNA2, respectively. The product was confirmed by DNA sequencing.

The plasmids carrying the short hairpin RNA were transfected into pancreatic cancer cells, using liposome Lipofectamine 2000 (Invitrogen-Life Technologies, Carlsbad, CA, USA), and subsequently cultured in the presence of $500 \mu \mathrm{g} / \mathrm{ml} \mathrm{G} 418$ (Gibco-BRL, Grand Island, NY, USA) for clonal selection.

Quantitative real-time PCR assays. Total RNA was extracted with TRIzol (Invitrogen-Life Technologies), according to the manufacturer's instructions. Following treatment with DNase I (Takara Biotechnology Co., Ltd., Dalian, China) at $37^{\circ} \mathrm{C}$ for $30 \mathrm{~min}$, RNA quantification was performed using spectrophotometry. The primers used for CD147, MCT1, MCT4 and $\beta$-actin are listed in Table II. The mRNA levels for CD147, MCT1, MCT4 and $\beta$-actin were analyzed by a onestep real-time reverse transcriptase polymerase chain reaction with RNA-direct ${ }^{\mathrm{TM}}$ SYBR-Green Real-time PCR Master Mix (Toyobo Co., Ltd., Osaka, Japan), according to the manufacturer's instructions. The cycling conditions were as follows: 40 cycles consisting of denaturation at $95^{\circ} \mathrm{C}$ for $5 \mathrm{sec}$, annealing at $60^{\circ} \mathrm{C}$ for $5 \mathrm{sec}$, and extension at $72^{\circ} \mathrm{C}$ for $30 \mathrm{sec}$. The $\mathrm{Ct}$ used in the real-time PCR quantification was defined as the PCR cycle number that crossed an arbitrarily chosen signal threshold in the log phase of the amplification curve. To verify the fold change of target gene expression, calculated $\mathrm{Ct}$ values were normalized to $\mathrm{Ct}$ values of $\beta$-actin amplified from the same sample $\left(\Delta \mathrm{Ct}=\mathrm{Ct}_{\text {target }}-\mathrm{Ct}_{\beta \text {-actin }}\right)$, and the $2^{-\Delta \Delta \mathrm{Ct}}$ method was used to calculate fold change (29). Each sample was prepared in triplicate, and all reactions were triplicated independently to ensure the reproducibility of the results.

Western blot analysis. The expression of CD147, MCT1 and MCT4 protein was evaluated by western blot analysis. Total protein was separated by SDS-PAGE on $12 \%$ gels and transferred to a polyvinylidene difluoride (PVDF) membrane. Skim milk powder (5\%) (soluble in TBST buffer solution) was used at room temperature under sealed conditions for $1 \mathrm{~h}$, with mouse anti-CD147 primary antibodies (1:500), rabbit anti-MCT1 primary antibodies (1:500), rabbit anti-MCT4 primary antibodies (1:500) and rabbit anti-human $\beta$-actin primary antibodies (1:500) incubated at room temperature for $2 \mathrm{~h}$, followed by incubation in a 1:2000 dilution of secondary antibodies conjugated to horseradish peroxidase (Santa Cruz Biotechnology, Santa Cruz, CA, USA) for $1 \mathrm{~h}$ at room temperature. The protein was visualized by ECL. All of the western blot analyses were performed at least three times.

Determination of intracellular lactate concentration. The change of intracellular lactate concentration in Panc-1 cells after CD147 silencing was assessed using a lactic acid assay kit (KeyGen Biotech Co., Ltd., Nanjing, China). This assay is based on the catalysis of lactate dehydrogenation by lactate dehydrogenase (LDH) to generate pyruvate by $\mathrm{NAD}^{+}$as hydrogen acceptors. Subsequently, nitroblue tetrazolium (NBT) is reduced to purple coloring when hydrogen is delivered to it from phenazine methosulphate (PMS). There is a linear relationship between the absorbance at $530 \mathrm{~nm}$ and the lactate concentration. Cells $\left(1 \times 10^{6}\right)$ were harvested by centrifugation, and cells were then ruptured by hypotonic salt solution for $1 \mathrm{~h}$ at room temperature. The supernatant was retained after centrifuging. The optical density was read at $530 \mathrm{~nm}$. Graphs are representative of three separate experiments.

In vitro invasion assay. Transwell plates (Corning Costar, Cambridge, MA, USA) were coated with basement membrane Matrigel $(20 \mathrm{mg} / \mathrm{ml}$, Becton-Dickinson, Franklin Lakes, NJ, USA) for $4 \mathrm{~h}$ at $37^{\circ} \mathrm{C}$. After the Matrigel solidified, $1 \times 10^{5}$ 
A

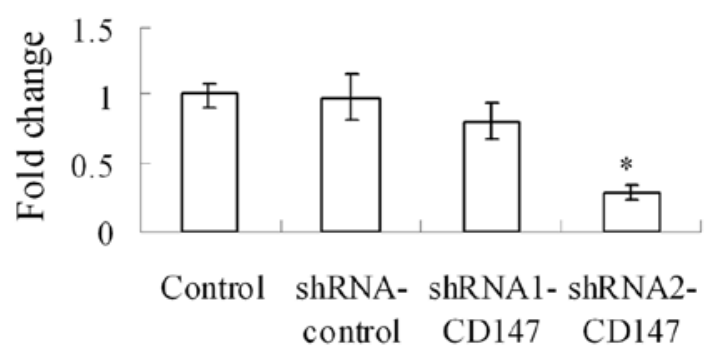

C

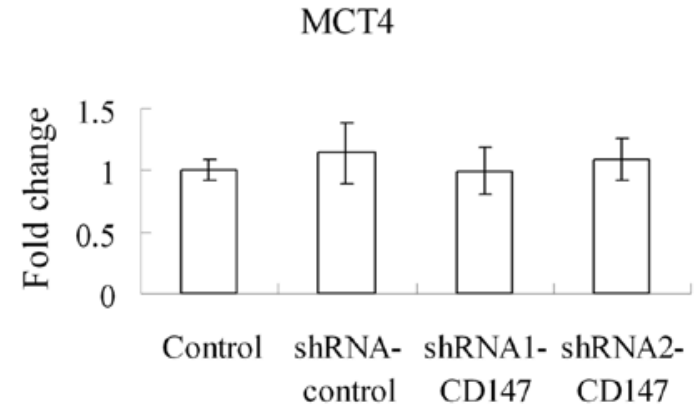

B

$\mathrm{MCT} 1$

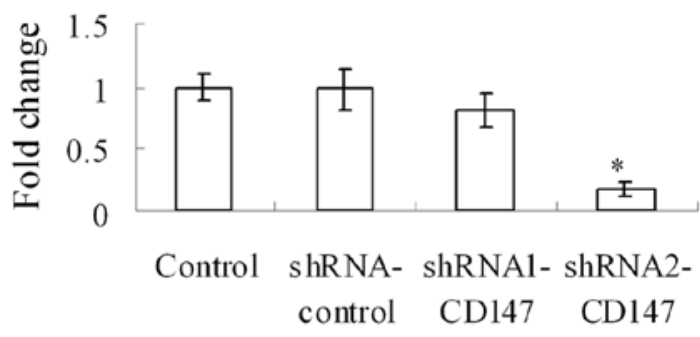

D

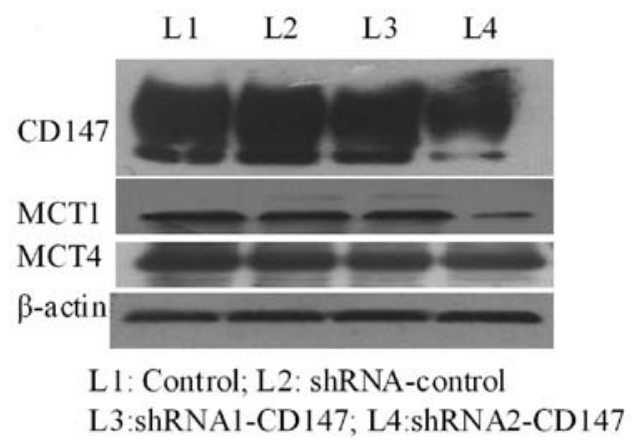

Figure 1. Expression levels of CD147, MCT1 and MCT4 in Panc-1 cells after CD147 silencing. Relative mRNA levels of (A) CD147 (B) MCT1 (C) MCT4 were analyzed by quantitative RT-PCR. $\beta$-actin was used as the normalization control. * $\mathrm{P}<0.01$ compared with the control group. Graphs are representative of three separate experiments. (D) Western blot analysis of CD147, MCT1 and MCT4 protein expression levels. $\beta$-actin was used as the loading control. The results show that the protein expression levels of CD147 and MCT1 were significantly downregulated by pH1-shRNA2 in Panc-1 cells. There was no significant change of MCT4 protein levels. The data were obtained from three independent experiments.

cells were seeded onto the Matrigel and incubated at $37^{\circ} \mathrm{C}$ for $24 \mathrm{~h}$. After $18 \mathrm{~h}$, cells that migrated through the permeable membrane were fixed with $100 \%$ methanol for $10 \mathrm{~min}$. The membrane with cells were soaked in $0.1 \%$ crystal violet for $10 \mathrm{~min}$ and then washed with distilled water. The number of cells attached to the lower surface of the polycarbonate filter was counted at $\mathrm{x} 400$ magnification under light microscopy. Each assay was carried out in triplicate and repeated three times.

Drug sensitivity assay. To assess their multidrug chemosensitivity, cells were plated in 96-well plates at a density of $1 \times 10^{4}$ cells/well and further incubated for $24 \mathrm{~h}$. The medium was then removed and replaced with fresh medium containing gemcitabine, paclitaxel, and oxaliplatin, respectively, with varying PPC (plasma peak concentrations, 0.1 PPC, 1.0 PPC and 10.0 PPC) for another $48 \mathrm{~h}$. After that, cells were stained with $20 \mu \mathrm{l}$ of sterile MTT dye [3-(4,5-dimethylthiazol-2-yl)2,5-diphenyltetrazolium bromide, $5 \mathrm{mg} / \mathrm{ml}$; Sigma] at $37^{\circ} \mathrm{C}$ for $4 \mathrm{~h}$, followed by removing the culture medium and mixing $150 \mu 1$ of dimethylsulfoxide (DMSO) thoroughly for $10 \mathrm{~min}$. Spectrometric absorbance at $490 \mathrm{~nm}$ was measured with a microplate reader. Each group was plated in three wells and was repeated three times.

In vivo metastasis assay. We used 4-6-week-old male BALB/c nude mice (Center for Comparative Medical Research of the Yangzhou University, Yangzhou, China). Cells were washed and resuspended in serum-free DMEM before inoculation. In each of the nude mice $(n=8), 2 \times 10^{5}$ cells in $200 \mu$ l culture medium were inoculated into the tail vein. Six weeks after inoculation, all animals were euthanized and the lungs were removed. Harvested tissues were fixed in $10 \%$ buffered formalin, embedded in paraffin, sectioned at $4 \mu \mathrm{m}$, and stained with H\&E. The antitumor effect was evaluated by counting the number of metastatic tumor clones on the surface of the lungs. All experiments were performed in accordance with institutional guidelines for the care and use of experimental animals.

Statistical analysis. Statistics were conducted by the SPSS software. Experimental data are presented as the mean \pm SD (standard deviation) and assessed by Student's t-tests and one-way ANOVA at a significance level of $\mathrm{P}<0.05$.

\section{Results}

shRNA targeting CD147 suppresses CD147 expression in Panc-1 cells. To better understand the role of CD147 in tumor cells, we established two recombinant vectors, including pH1-shRNA1 and pH1-shRNA2. As demonstrated by quantitative reverse transcription PCR (qRT-PCR), pH1-shRNA2 effectively inhibited expression of CD147 in tumor cells $(\mathrm{P}<0.01)$ (Fig. 1A). In addition, western blot analysis confirmed the downregulation of CD147 protein by $\mathrm{pH} 1-\mathrm{shRNA} 2$ $(\mathrm{P}<0.01)$ (Fig. 1D).

CD147 silencing inhibits MCT1 and MCT4 expression. Many studies have demonstrated that the functionality of MCT1 and MCT4, natural transporters of lactate, on mitochondrial membranes depends on the association with the mature, 
A

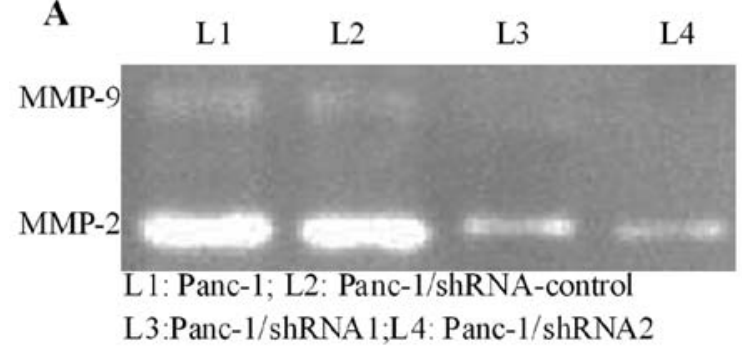

B

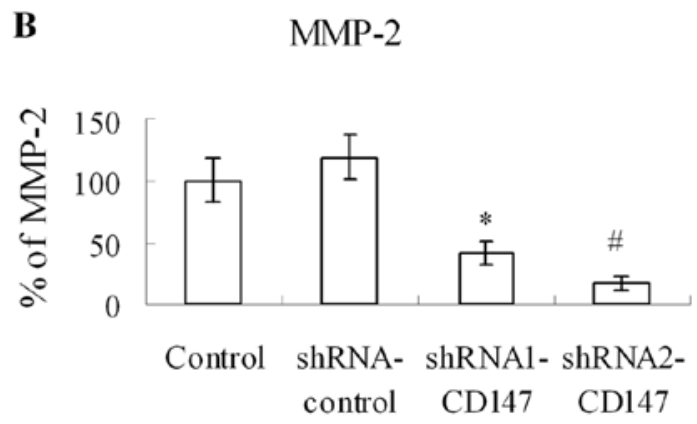

C

MMP-9

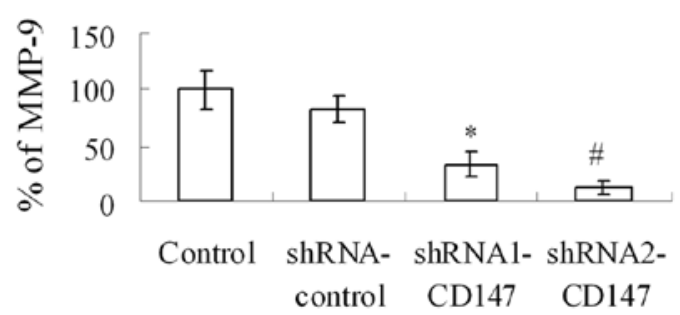

Figure 2. Activities of MMP-2 and MMP-9 in Panc-1 cells after CD147 silencing. Cells were incubated for $24 \mathrm{~h}$ and conditioned media were used for the measurement of MMP-2 and MMP- 9 protein levels by gelatin zymography. (A) Photographs of the MMP-2 and MMP-9 bands, which are representative of three independent experiments. Quantitative analysis of the (B) MMP-2 bands and (C) the MMP-9 bands. "P<0.01 compared with the control. ${ }^{\text {}} \mathrm{P}<0.01$ compared with the control. Graphs are representative of three separate experiments.

glycosylated form of CD147. We thus examined whether CD147 silencing could reduce the expression of MCT1 and MCT4. As demonstrated by qRT-PCR, the mRNA expression of MCT1 was downregulated by pH1-shRNA2 in the Panc-1 cell line $(\mathrm{P}<0.01)$, but the expression of MCT4 was not significantly altered $(\mathrm{P}>0.05)$ (Fig. $1 \mathrm{~B}$ and $\mathrm{C})$. In addition, western blot analysis confirmed the downregulation of MCT1 protein by pH1-shRNA2 in the Panc-1 cell line. Furthermore, there was no significant change of the MCT4 protein (Fig. 1D).

CD147 silencing reduces MMP-2 and MMP-9 activities. CD147 has been suggested to induce MMP in tumor-associated mesenchymal cells, so we examined whether CD147 silencing could reduce the activities of MMP-2 and MMP-9, using gelatin zymography. The activities of MMP-2 and MMP-9 were reduced significantly by pH1-shRNA2 in the Panc-1 cell line, compared with the control group $(\mathrm{P}<0.01)$; and there was no significant difference between the $\mathrm{pH} 1$-shRNA-control group and the corresponding controls ( $\mathrm{P}>0.05)$ (Fig. 2).

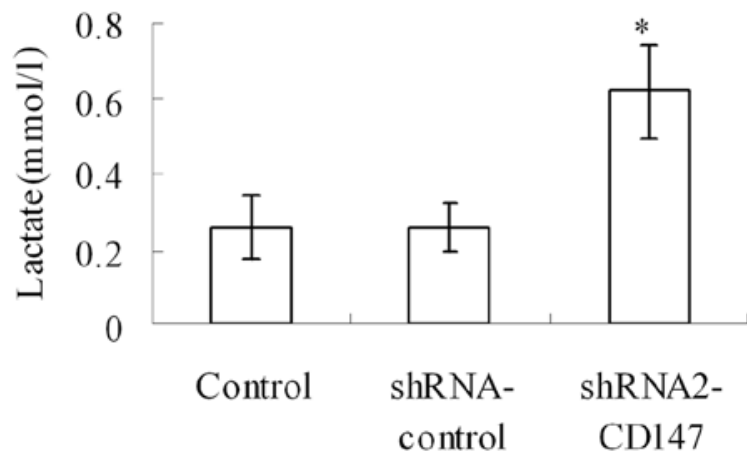

Figure 3. Intracellular lactate in Panc-1 cells after CD147 silencing. Panc-1 cells were transfected with pH1-shRNA2-CD147. CD147 silencing increased the intracellular lactate concentration $(\mathrm{P}<0.01)$. Transfection with $\mathrm{pH} 1-$ shRNA2-control served as a negative control. The graph is representative of three separate experiments.

CD147 silencing inhibits the function of lactate transporters. We then examined whether CD147 silencing inhibited the function of lactate transporters. To confirm that the downregulation of MCT1 expression by pH1-shRNA2 inhibits the function of these transporters we assessed the intracellular lactate concentration in Panc-1 cells. As shown in Fig. 3, the CD147 silencing induced an increase of the intracellular lactate concentration in Panc-1 cells $(\mathrm{P}<0.01)$. This demonstrates that the CD147 silencing-induced decrease in MCT1 expression is associated with an increase in intracellular lactate concentration.

Inhibition of CD147 alters tumor cell invasion in vitro. To examine whether the downregulation of CD147 in Panc-1 cells affected its invasive ability, we performed an in vitro Matrigel transwell analysis. The results showed that silencing of CD147 significantly reduced invasion activities in Panc-1 cells when compared with corresponding controls $(\mathrm{P}<0.05)$ (Fig. 4).

CD147 silencing increases the sensitivity to chemotherapeutic drugs. CD147 has been found to be overexpressed in multidrug resistance tumor cells and could confer resistance to some antitumor drugs. To examine whether the downregulation of CD147 in Panc-1 cells affected its sensitivity to chemotherapeutic drugs, we assessed whether CD147 silencing induced an alteration in the chemosensitivity of Panc- 1 cells to various agents by the MTT assay. As shown in Fig. 5, CD147 silencing significantly increased the chemosensitivity of Panc-1 cells to gemcitabine at 1.0 PPC and 10.0 PPC but not at $0.1 \mathrm{PPC}$ compared with the control groups $(\mathrm{P}<0.05)$. The results also show that there was no significant change of the chemosensitivity induced by CD147 silencing to paclitaxel and oxaliplatin in Panc-1 cells $(\mathrm{P}>0.05)$.

CD147 silencing inhibited the metastatic potential of Panc-1 cells. To investigate the effect of CD147 silencing on Panc-1cell metastasis, we injected cells $\left(2 \times 10^{5} / 200 \mu \mathrm{l}\right)$ into the tail vein of nude mice and evaluated the presence of metastatic nodes in the lungs after 6 weeks. We observed a significant reduction in the number of metastatic nodes in the mice that received Panc-1 cells stably transfected with CD147, as compared with the corresponding controls $(\mathrm{P}<0.01)$ (Fig. 6). 
A

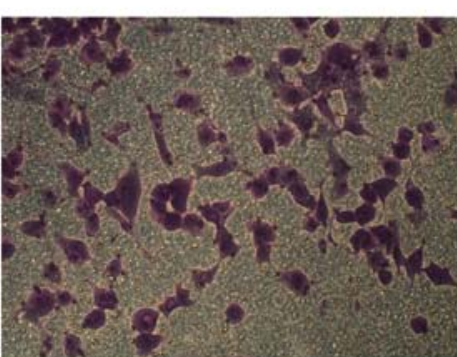

Control

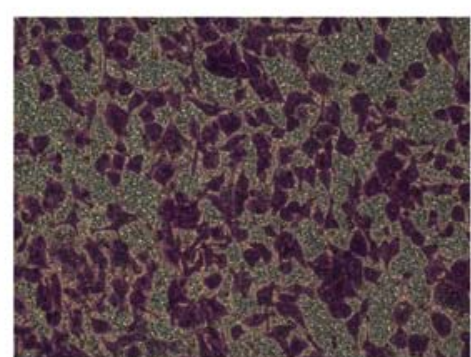

shRNA-control

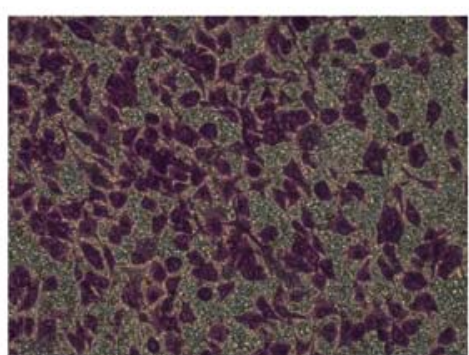

shRNA-CD147

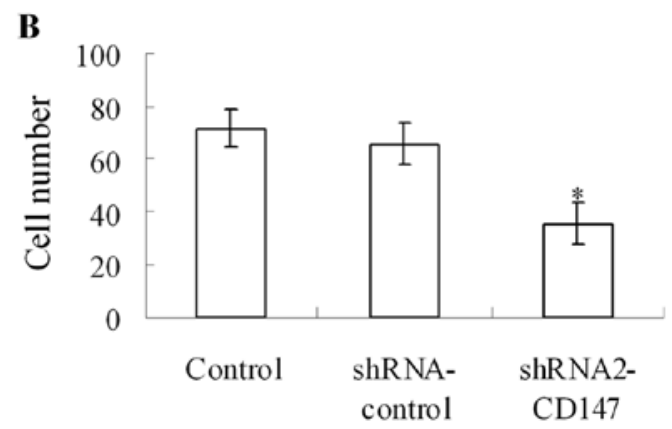

Figure 4. Invasive ability of Panc-1 cells after CD147 silencing. Using a Matrigel polycarbonate filter, $1 \times 10^{5}$ cells were seeded in the Millicell upper chamber (A) Representative images of cells invading the Matrigel (x400). (B) The number of cells that invaded through the chamber was averaged. The invading cells were counted as a sum of 10 fields of vision under a microscope. ${ }^{*} \mathrm{P}<0.01$ compared with control group. The graph is representative of three separate experiments.
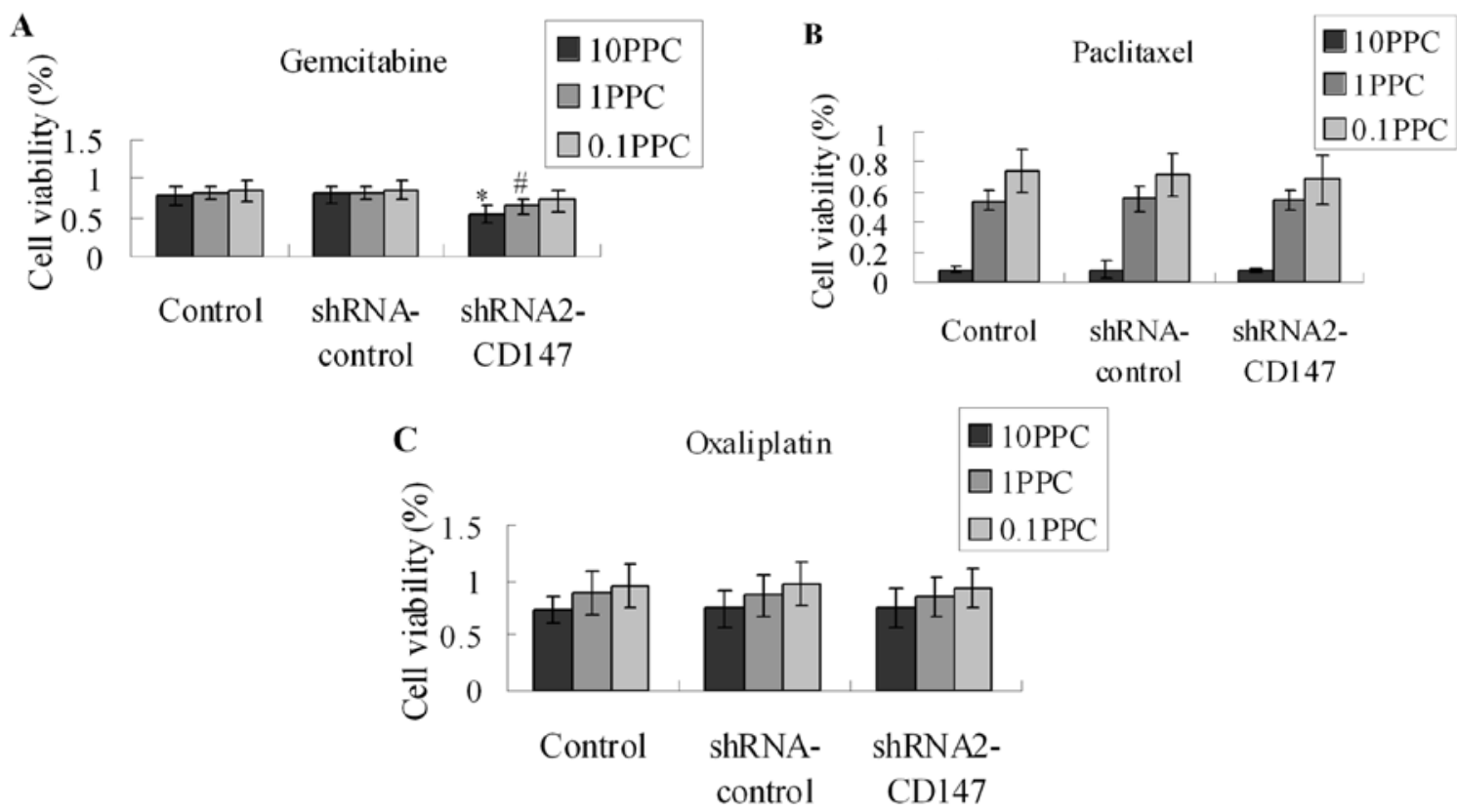

Figure 5. Multidrug chemosensitivity of Panc-1 cells after CD147 silencing. (A) Cells were treated with gemcitabine with varying plasma peak concentrations (PPC; 0.1, 1.0 and 10.0 PPC) for $48 \mathrm{~h}$. Cell viability was determined by the MTT assay. CD147 silencing significantly increased the chemosensitivity of Panc-1 cells to gemcitabine at 1.0 PPC and $10.0 \mathrm{PPC}$ compared with the control groups $\left({ }^{*} \mathrm{P}<0.05,{ }^{*} \mathrm{P}<0.05\right)$. The graphs are representative of three separate experiments. Cells were treated with (B) paclitaxel or (C) oxaliplatin with varying PPC (0.1, 1.0 and 10.0 PPC) for $48 \mathrm{~h}$. Cell viability was determined by the MTT assay. The results show that there was no significant change of the chemosensitivity induced by CD147 silencing to paclitaxel or oxaliplatin in Panc-1 cells $(\mathrm{P}>0.05)$. Graphs are representative of three separate experiments.

\section{Discussion}

CD147 is a multifunctional glycoprotein that has been shown to increase tumor invasion. It plays an important role in cancer progression, such as promoting invasiveness via the stimulation of matrix metalloproteinase production (MMPs), interacting with certain lactate transporters (MCT1 and MCT4) and facilitating their expression on the cell surface, and mediating multidrug resistance via the hyaluronan-mediated upregulation of ErbB2 signaling and cell survival pathway activities $(13,26,30)$. CD147 is highly expressed on the surface of various tumors, including pancreatic cancer $(31,32)$; however, the molecular mechanisms involved and the role of CD147 in pancreatic cancer remain poorly understood. In the present study, we constructed the CD147 shRNA expression vector to inhibit the expression of CD147 in the pancreatic cancer cell 
$\mathbf{A}$

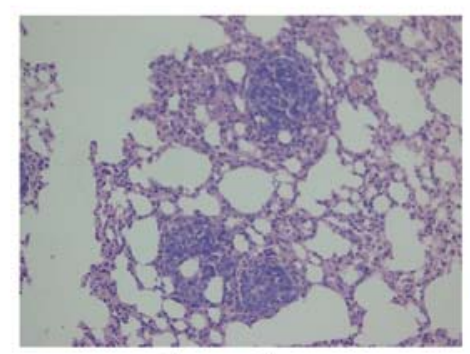

Control

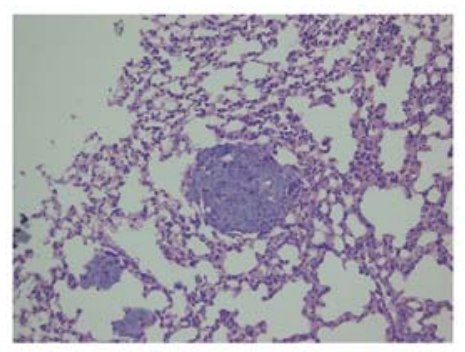

shRNA-control

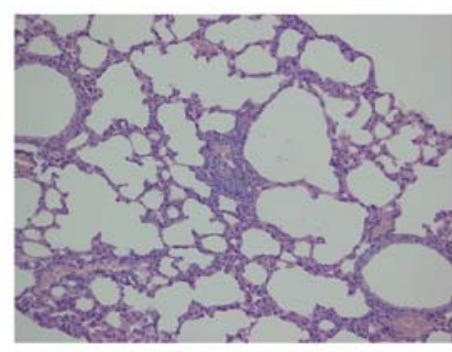

shRNA-CD147

B

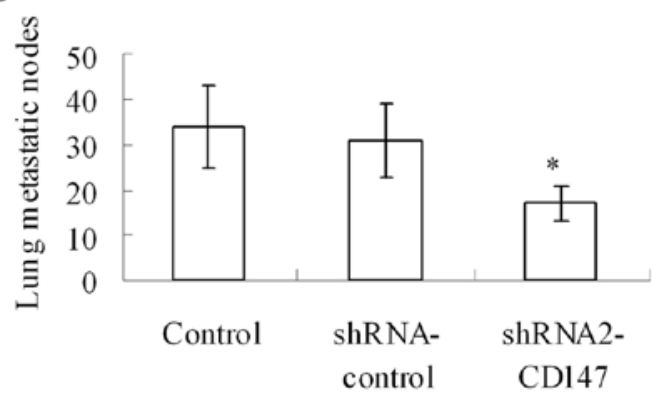

Figure 6. CD147 silencing inhibits the metastatic nodes in the lungs. A volume of $2 \times 10^{5}$ cells $/ 200 \mu 1$ was injected into each of the nude mice through the tail vein. (A) Microscope images show that CD147 silencing significantly inhibits the lung metastatic nodes after inoculation with Panc-1 cells (H\&E staining). Magnification, $x 200$. (B) The number of lung metastatic nodes. ${ }^{*} \mathrm{P}<0.01$ compared with the control group.

line in order to investigate the role of CD147 silencing in invasion, metastasis, and multidrug resistance of pancreatic cancer.

Tumor cell invasion and metastasis are the main causes of treatment failure and mortality in patients. CD147 can stimulate the production of MMPs, thereby leading to extracellular matrix degradation and increased tumor invasion and metastasis. It has been reported that the expression of MMP-2 and MMP-9 is correlated with the invasion and local recurrence rate in pancreatic cancer cells (33-35). Transfection of CD147 cDNA into human MDA-MB-436 breast cancer cells resulted in an enhancement of tumor growth and an increase in metastatic incidences, both of which were directly correlated with high levels of tumor-derived MMP-2 and MMP-9 (36). In the present study, the results showed that CD147 silencing in human pancreatic cancer cells reduced the secretion of MMP-2 and MMP-9 and inhibited the invasion and metastasis ability of pancreatic cancer cells in vitro. This was consistent with previous studies (33-35).

CD147, by its close association with MCT1 and MCT4, plays a pivotal role in the glycolysis reflected by the transmembrane transport of lactate and the regulation of cell proliferation. Tumor cell expression of MCT1 and MCT4 has been reported to be regulated by CD147, which facilitates their cell surface expression, so CD147 plays a pivotal role in the glycolysis reflected by the transmembrane transport of lactate and the regulation of cell proliferation (37). MCT1 inhibition has also been shown to have antitumor potential against in vivo models of lung carcinoma, colorectal carcinoma, and a squamous carcinoma cell line after a cyano-4-hydroxycinnamate-mediated MCT1 inhibition (38). The present results showed that CD147 silencing resulted in a significant reduction of MCT1, but not MCT4 expression, which supports the concept that CD147 is an ancillary protein required for the expression of MCT1. The results also showed that CD147 silencing resulted in an increase of the intracellular lactate concentration in pancreatic cancer cells. The increase of lactate concentration

may inhibit the cell growth, since lactate has been demonstrated to decrease pyruvate reduction to lactate by inhibition of (LDH) (39). However, the present results did not show that the increase of lactate concentration inhibited the proliferation in Panc-1 cells (data not shown), and we will investigate the mechanism in the future.

Multidrug resistance is a major obstacle in the treatment of pancreatic cancer, and upregulation of CD147 has been reported in multidrug resistant cancer cells. The relationship between tumor metastasis and multidrug resistance is not fully defined in pancreatic cancer, although indirect evidence in the advanced disease suggests a functional link between these processes. In the present study, CD147 silencing increased the chemosensitivity to gemcitabine, but not to paclitaxel and oxaliplatin in Panc-1 cells, suggesting that the expression of CD147 is closely related to multidrug resistance in pancreatic cancer. Gemcitabine is the first-line chemotherapeutic agent for advanced adenocarcinoma of pancreatic cancer; however, chemoresistance to gemcitabine remains a major cause of failure for the clinical treatment of this disease. Studies have indicated that resistance to gemcitabine is dependent on mitochondria-mediated apoptosis, but various mediators of gemcitabine-mediated apoptosis have been described (40-43). The precise mechanism is not fully understood.

Collectively, these observations identify CD147 as a key regulator of the invasion, metastasis, and multidrug resistance in pancreatic cancer cells and suggest that patients with this malignancy may benefit from targeted therapies blocking effectors of this signaling pathway.

\section{Acknowledgements}

This project was supported by grants from the National Nature Science Foundation of China (no. 81172141), Nanjing Science and Technology Committee project (no. 201108025), and Nanjing Medical Technology Development Project (no. ZKX11025). 


\section{References}

1. Li D, Xie K, Wolff R and Abbruzzese JL: Pancreatic cancer. Lancet 363: 1049-1057, 2004.

2. Vernejoul F, Faure P, Benali N, et al: Antitumor effect of in vivo somatostatin receptor subtype 2 gene transfer in primary and metastatic pancreatic cancer models. Cancer Res 62: 6124-6131, 2002.

3. Torrisani $\mathbf{J}$ and Buscail L: Molecular pathways of pancreatic carcinogenesis. Ann Pathol 22: 349-355, 2002.

4. Korc M: Pathways for aberrant angiogenesis in pancreatic cancer Mol Cancer 2: 8, 2003.

5. Suzuki S, Sato M, Senoo H and Ishikawa K: Direct cell-cell interaction enhances pro-MMP-2 production and activation in co-culture of laryngeal cancer cells and fibroblasts: involvement of EMMPRIN and MT1-MMP. Exp Cell Res 293: 259-266, 2004.

6. Riethdorf S, Reimers N, Assmann V, Kornfeld JW, Terracciano L, Sauter $\mathrm{G}$ and Pantel K: High incidence of EMMPRIN expression in human tumors. Int J Cancer 119: 1800-1810, 2006.

7. Muramatsu T and Miyauchi T: Basigin (CD147): a multifunctional transmembrane protein involved in reproduction, neural function, inflammation and tumor invasion. Histol Histopathol 18: 981-987, 2003.

8. Kaname T, Miyauchi T, Kuwano A, Matsuda Y, Muramatsu T and Kajii T: Mapping basigin (BSG), a member of the immunoglobulin superfamily, to 19p13.3. Cytogenet Cell Genet 64: 195-197, 1993

9. Fadool JM and Linser PJ: 5A11 antigen is a cell recognition molecule which is involved in neuronal-glial interactions in avian neural retina. Dev Dyn 196: 252-262, 1993.

10. Biswas C, Zhang Y, DeCastro R, Guo H, Nakamura T, Kataoka H and Nabeshima K: The human tumor cell-derived collagenase stimulatory factor (renamed EMMPRIN) is a member of the immunoglobulin superfamily. Cancer Res 55: 434-439, 1995.

11. Schneiderhan W, Diaz F, Fundel M, et al: Pancreatic stellate cells are an important source of MMP-2 in human pancreatic cancer and accelerate tumor progression in a murine xenograft model and CAM assay. J Cell Sci 120: 512-519, 2007.

12. Kanekura T, Chen X and Kanzaki T: Basigin (CD147) is expressed on melanoma cells and induces tumor cell invasion by stimulating production of matrix metalloproteinases by fibroblasts. Int J Cancer 99: 520-528, 2002.

13. Kirk P, Wilson MC, Heddle C, Brown MH, Barclay AN and Halestrap AP: CD147 is tightly associated with lactate transporters MCT1 and MCT4 and facilitates their cell surface expression. EMBO J 19: 3896-3904, 2000.

14. Wilson MC, Meredith D, Fox JE, Manoharan C, Davies AJ and Halestrap AP: Basigin (CD147) is the target for organomercurial inhibition of monocarboxylate transporter isoforms 1 and 4: the ancillary protein for the insensitive MCT2 is EMBIGIN (gp70). J Biol Chem 280: 27213-27221, 2005.

15. Philp NJ, Ochrietor JD, Rudoy C, Muramatsu T and Linser PJ Loss of MCT1, MCT3, and MCT4 expression in the retinal pigment epithelium and neural retina of the 5A11/basigin-null mouse. Invest Ophthalmol Vis Sci 44: 1305-1311, 2003.

16. Izumi $\mathrm{H}$, Torigoe $\mathrm{T}$, Ishiguchi $\mathrm{H}$, et al: Cellular $\mathrm{pH}$ regulators: potentially promising molecular targets for cancer chemotherapy. Cancer Treat Rev 29: 541-549, 2003.

17. Fang JS, Gillies RD and Gatenby RA: Adaptation to hypoxia and acidosis in carcinogenesis and tumor progression. Semin Cancer Biol 18: 330-337, 2008

18. Wahl ML, Owen JA, Burd R, et al: Regulation of intracellular $\mathrm{pH}$ in human melanoma: potential therapeutic implications. Mol Cancer Ther 1: 617-628, 2002.

19. Halestrap AP and Meredith D: The SLC16 gene family-from monocarboxylate transporters (MCTs) to aromatic amino acid transporters and beyond. Pflugers Arch 447: 619-628, 2004.

20. Halestrap AP and Price NT: The proton-linked monocarboxylate transporter (MCT) family: structure, function and regulation. Biochem J 343: 281-299, 1999.

21. Bröer S, Bröer A, Schneider HP, Stegen C, Halestrap AP and Deitmer JW: Characterization of the high-affinity monocarboxylate transporter MCT2 in Xenopus laevis oocytes. Biochem J 341: 529-535, 1999.
22. Grollman EF, Philp NJ, McPhie P, Ward RD and Sauer B: Determination of transport kinetics of chick MCT3 monocarboxylate transporter from retinal pigment epithelium by expression in genetically modified yeast. Biochemistry 39 9351-9357, 2000.

23. Dimmer KS, Friedrich B, Lang F, Deitmer JW and Bröer S: The low-affinity monocarboxylate transporter MCT4 is adapted to the export of lactate in highly glycolytic cells. Biochem J 350: 219-227, 2000

24. Manning Fox JE, Meredith D and Halestrap AP: Characterisation of human monocarboxylate transporter 4 substantiates its role in lactic acid efflux from skeletal muscle. J Physiol 529: 285-293, 2000.

25. Poole RC and Halestrap AP: Interaction of the erythrocyte lactate transporter (monocarboxylate transporter 1) with an integral 70-kDa membrane glycoprotein of the immunoglobulin superfamily. J Biol Chem 272: 14624-14628, 1997.

26. Misra S, Ghatak S, Zoltan-Jones A and Toole BP: Regulation of multidrug resistance in cancer cells by hyaluronan. J Biol Chem 278: 25285-25288, 2003.

27. Yang JM, Xu Z, Wu H,Zhu H, Wu X and Hait WN: Overexpression of extracellular matrix metalloproteinase inducer in multidrug resistant cancer cells. Mol Cancer Res 1: 420-427, 2003.

28. Marieb EA, Zoltan-Jones A, Li R, et al: Emmprin promotes anchorage-independent growth in human mammary carcinoma cells by stimulating hyaluronan production. Cancer Res 64 : 1229-1232, 2004

29. Livak KJ and Schmittgen TD: Analysis of relative gene expression data using real-time quantitative PCR and the 2(-Delta Delta C(T)) method. Methods 25: 402-408, 2001

30. Toole BP: Hyaluronan: from extracellular glue to pericellular cue. Nat Rev Cancer 4: 528-539, 2004

31. Li M, Wang H, Li F, Fisher WE, Chen C and Yao Q: Effect of cyclophilin A on gene expression in human pancreatic cancer cells. Am J Surg 190: 739-745, 2005.

32. Li M, Zhai Q, Bharadwaj U, et al: Cyclophilin A is overexpressed in human pancreatic cancer cells and stimulates cell proliferation through CD147. Cancer 106: 2284-2294, 2006.

33. Zhang W, Erkan M, Abiatari I, et al: Expression of extracellular matrix metalloproteinase inducer (EMMPRIN/CD147) in pancreatic neoplasm and pancreatic stellate cells. Cancer Biol Ther 6: 218-227, 2007.

34. Yang X, Staren ED, Howard JM, Iwamura T, Bartsch JE and Appert HE: Invasiveness and MMP expression in pancreatic carcinoma. J Surg Res 98: 33-39, 2001.

35. Koshiba T, Hosotani R, Wada M, et al: Involvement of matrix metalloproteinase- 2 activity in invasion and metastasis of pancreatic carcinoma. Cancer 82: 642-650, 1998.

36. Zucker S, Hymowitz M, Rollo EE, et al: Tumorigenic potential of extracellular matrix metalloproteinase inducer. Am J Pathol 158: 1921-1928, 2001

37. Su J, Chen X and Kanekura T: A CD147-targeting siRNA inhibits the proliferation, invasiveness, and VEGF production of human malignant melanoma cells by down-regulating glycolysis. Cancer Lett 273: 140-277, 2009.

38. Sonveaux P, Végran F, Schroeder T, et al: Targeting lactatefueled respiration selectively kills hypoxic tumor cells in mice. J Clin Invest 118: 3930-3942, 2008.

39. Omasa T, Higashiyama K, Shioya S and Suga K: Effects of lactate concentration on hybridoma culture in lactate-controlled fed-batch operation. Biotechnol Bioeng 39: 556-564, 1992.

40. Schniewind B, Christgen M, Kurdow R, Haye S, Kremer B, Kalthoff $\mathrm{H}$ and Ungefroren $\mathrm{H}$ : Resistance of pancreatic cancer to gemcitabine treatment is dependent on mitochondria-mediated apoptosis. Int J Cancer 109: 182-188, 2004.

41. Yang C, Kaushal V, Shah SV and Kaushal GP: Mcl-1 is downregulated in cisplatin-induced apoptosis, and proteasome inhibitors restore $\mathrm{Mcl}-1$ and promote survival in renal tubular epithelial cells. Am J Physiol Renal Physiol 292: F1710-F1717, 2007.

42. Cascalló M, Calbó J, Capellà G, Fillat C, Pastor-Anglada M and Mazo A: Enhancement of gemcitabine-induced apoptosis by restoration of $\mathrm{p} 53$ function in human pancreatic tumors. Oncology 68: 179-189, 2005.

43. Koizumi K, Tanno S, Nakano Y, et al: Activation of p38 mitogenactivated protein kinase is necessary for gemcitabine-induced cytotoxicity in human pancreatic cancer cells. Anticancer Res 25: 3347-3353, 2005 . 